\title{
A Stepwise Approach to Transanal Endoscopic Microsurgery for Rectal Cancer Using a Single-Incision Laparoscopic Port
}

\author{
Roger A. Smith, MD', Daniel A. Anaya, $\mathrm{MD}^{1,2}$, Daniel Albo, $\mathrm{MD}^{1}$, and Avo Artinyan, MD MS ${ }^{1,2}$ \\ ${ }^{1}$ Michael E. DeBakey Department of Surgery, Baylor College of Medicine, Houston, TX; ${ }^{2}$ Operative Care Line, Michael \\ E. DeBakey VA Medical Center, Houston, TX
}

\begin{abstract}
Background. Radical rectal resection with total mesorectal excision is the current standard of care for the operative treatment of rectal cancer. Local excision is an acceptable alternative in selected patients with early disease $\left(\mathrm{T}_{\text {is }} 0-\mathrm{T}_{1}\right)$ and low-risk features, in whom radical resection may be associated with unacceptably high morbidity. With recent data demonstrating favorable results in well-selected patients, the role of local excision for rectal cancer is expanding. ${ }^{1,2}$ Transanal endoscopic microsurgery (TEM), which requires the use of an operating anoscope, has been used for the local excision of mid-upper rectal tumors. We describe an alternative approach to TEM for rectal cancer.
\end{abstract}

Methods. We present a stepwise technique for TEM using a single-incision laparoscopic (SILS) port. The patient is a 64 year-old male with a right anterolateral rectal polyp $7 \mathrm{~cm}$ from the anal verge, which on snare polypectomy demonstrated in-situ carcinoma with positive margins. Endoscopic ultrasound demonstrated $\mathrm{uT}_{1}$ disease with no lymphadenopathy. He opted for local excision and underwent TEM. Our stepwise approach includes: (1) delineation of excision margins, (2) full thickness incision of the rectal wall, (3) circumferential dissection, and full thickness excision, and (4) suture repair.

Electronic supplementary material The online version of this article (doi:10.1245/s10434-012-2359-6) contains supplementary material, which is available to authorized users.

(C) Society of Surgical Oncology 2012

First Received: 11 October 2011;

Published Online: 24 April 2012

A. Artinyan, MD MS

e-mail: artinyan@bcm.edu
Results. The procedure was performed without intraoperative or postoperative complications. Final pathology revealed in-situ carcinoma with widely negative margins. At 1- and 3-week follow-up visits, the patient was pain free with normal bowel activity and no rectal bleeding or genitourinary dysfunction.

Discussion. TEM using a SILS port is an effective technique for the local excision of mid-upper rectal cancer in well-selected patients.

DISCLOSURE The views expressed in this article are those of the authors and do not necessarily represent the views of the Department of Veterans Affairs. Dr. Daniel Albo serves as a consultant for Covidien, Inc. and Applied Medical Resources Corporation.

\section{REFERENCES}

1. Lezoche G, Guerrieri M, Baldarelli M, Paganini AM, D'Ambrosio G, Campagnacci R, et al. Transanal endoscopic microsurgery for 135 patients with small nonadvanced low rectal cancer (iT1-iT2, iN0): short- and long-term results. Surg Endosc. 2011;25:1222-9.

2. Blair S, Ellenhorn JD. Transanal excision for low rectal cancers is curative in early-stage disease with favorable histology. Am Surg. 2000;66:817-20. 